\title{
OTIMIZAÇÃO DAS CONDIÇÕES DE OPERAÇÃO NO PROCESSO DE CLARIFICAÇÃO DE ÁGUA SUPERFICIAL POR MEIO DA ASSOCIAÇÃO DOS COAGULANTES Moringa oleifera Lam E CLORETO FÉRRICO
}

Karina Cardoso Valverde ${ }^{1}$

Priscila Ferri Coldebella ${ }^{2}$

Rosângela Bergamasco ${ }^{3}$

RESUMO: Informações sobre as condições de operação no processo de clarificação ainda são escassas na literatura, principalmente relacionadas aos efeitos do uso de coagulantes químicos em conjunto com a Moringa oleifera Lam (MO). Assim, esse estudo propõe otimizar as condições de operação do processo de coagulação/floculação e sedimentação, por meio de ensaios em Jar Test realizados com a alteração das velocidades de mistura rápida (VMR) e lenta (VML), tempos de mistura (TMR e TML) e sedimentação (TS), para a associação do coagulante MO e cloreto férrico. Utilizou-se água superficial proveniente da bacia do rio Pirapó, Maringá, PR, com turbidez inicial de 72,9 NTU e as dosagens de coagulantes adicionadas nos ensaios foram de $10 \mathrm{mg} \cdot \mathrm{L}^{-1} \mathrm{e}$ $50 \mathrm{mg} \cdot \mathrm{L}^{-1}$ para o cloreto férrico e $\mathrm{MO}$, respectivamente. Para a avaliação da remoção dos

\footnotetext{
${ }^{1}$ Engenheira Química, Acadêmica de Pós-graduação em Engenharia Química (Doutorado), Universidade Estadual de Maringá (UEM), Maringá, PR, Bolsista CAPES. ka.cc@bol.com.br

${ }^{2}$ Engenheira Química, Acadêmica de Pós-graduação em Engenharia Química (Doutorado), Universidade Estadual de Maringá (UEM), Maringá, PR, Bolsista CAPES. priscila.ferri@bol.com.br

${ }^{3}$ Docente do Curso de Engenharia Química, Universidade Estadual de Maringá (UEM), Maringá, PR, Bolsista de Produtividade em Pesquisa CNPq. rosangela@deq.uem.br
} 
parâmetros de qualidade utilizou-se delineamento fatorial $27 \times 4$, sendo vinte e sete variações quanto à velocidade de mistura (VMR e VML) e tempos de mistura (TMR e TML); e quatro tempos de sedimentação (TS). Verificou-se que os parâmetros de mistura afetam a eficiência de remoção dos parâmetros de qualidade. Por meio da aplicação do teste Tukey, as condições de operação foram: 100 rpm (VMR), 3 min (TMR), 30 rpm (VML) e 15 min (TML), com eficiências de remoção de $89,7 \%, 90,8 \%$ e $73,5 \%$ para os parâmetros cor aparente, turbidez e compostos com absorção em $U_{254 n m}$, respectivamente.

Palavras chaves: Clarificação da água. Moringa oleifera Lam. Cloreto férrico.

\section{INTRODUÇÃO}

A adição de coagulantes tem por objetivo auxiliar a remoção das impurezas físicas, químicas e microbiológicas presentes na água superficial.

Pritchard et al. (2010) afirmam que, a mistura rápida é importante após a adição de um coagulante para assegurar uma dispersão uniforme e aumentar a oportunidade de contato entre as partículas.

Já a floculação é uma das operações que visa reduzir o número de partículas presentes na água superficial.

$\mathrm{Na}$ etapa de sedimentação, aos flocos formados nos processos anteriores são fornecidas condições que os permitam depositar pela ação da gravidade.

Vale ressaltar que, o fenômeno coagulação/floculação e sedimentação, propicia a clarificação da água.

Em relação à utilização de coagulantes químicos, o cloreto férrico é representado pela fórmula molecular $\mathrm{FeCl}_{3} \cdot 6 \mathrm{H}_{2} \mathrm{O}$ e produz bons flocos no intervalo de $\mathrm{pH}$ entre 5 e 11 .

Atualmente, a utilização de coagulantes naturais tais como a Moringa oleifera Lam (MO) tem sido estudada como uma opção ao tratamento de água convencional. Segundo Lo Monaco et al. (2010), a utilização desses coagulantes pode proporcionar atenuação nos problemas ligados ao consumo de água não potável e despejos de águas residuárias, sem tratamento, em corpos hídricos receptores. 
A MO trata-se de uma planta de múltiplo uso (NDABIGENGESERE e NARASIAH, 1998; MANGALE SAPANA et al., 2012). Folhas, frutos verdes, flores e sementes são ditas como sendo de valor alimentar e medicinal (LEA, 2010; DUBEY et al., 2013).

Amagloh e Benang (2009) afirmam que, quando o pó das sementes de MO é adicionado à água turva, as proteínas liberam cargas positivas atraindo as partículas carregadas negativamente presentes na água.

Quanto às vantagens, a MO não altera significativamente o pH (ABALIWANO et al., 2008) e a alcalinidade da água após o tratamento (NDABIGENGESERE e NARASIAH, 1998; PISE e HALKUDE, 2012), não causa problemas de corrosão (GHEBREMICHAEL et al., 2005), e não é tóxica para o homem (LEA, 2010; MANGALE SAPANA et al., 2012).

Considerando o fato de que a MO pode ser produzida localmente, o seu uso como coagulante na purificação de água deve ser incentivado (AMAGLOH e BENANG, 2009).

Como estudos considerando a associação da $\mathrm{MO}$ com os coagulantes químicos são escassos na literatura, torna-se interessante estudar o comportamento dessa combinação em termos de eficiência de remoção dos parâmetros de qualidade.

Segundo Baghvand et al. (2009), os parâmetros de mistura, incluindo o tempo e intensidade, podem afetar a eficiência de remoção de turbidez e deste modo, devem ser investigados.

Assim, esse estudo propõe otimizar as condições de operação do processo de coagulação/floculação e sedimentação, por meio de ensaios realizados com a alteração das velocidades de mistura rápida (VMR) e lenta (VML), tempos de mistura (TMR e TML) e sedimentação (TS), para a associação do coagulante MO e cloreto férrico.

\section{MATERIAIS E MÉTODOS}

Os ensaios de clarificação foram realizados no Laboratório de Gestão, Controle e Preservação Ambiental, do Departamento de Engenharia Química (DEQ), da Universidade Estadual de Maringá (UEM), utilizando a água superficial coletada na Companhia de Saneamento do Paraná (SANEPAR), proveniente da bacia do rio Pirapó, Maringá, PR, Brasil. 
Para a preparação da solução padrão do coagulante cloreto férrico, foi considerada uma concentração de $1 \% \mathrm{~m} / \mathrm{v}$. Para a obtenção do coagulante em pó de $\mathrm{MO}, 5 \mathrm{~g}$ de sementes foram descascadas, trituradas em liquidificador (NL-41 Mondial) e secas em estufa com circulação e renovação de ar (Digital Timer $\mathrm{SX} C R / 42$ ) a $40^{\circ} \mathrm{C}$ até peso constante (AMAGLOH e BENANG, 2009).

Os ensaios de clarificação da água foram realizados em Jar Test Nova Ética Modelo 218/LDB06 de seis provas em recipientes com $700 \mathrm{~mL}$ de água superficial. A temperatura da água foi mantida na faixa de $25,0 \pm 3,0^{\circ} \mathrm{C}$ (VALVERDE et al., 2013).

As dosagens de coagulantes adicionadas nos ensaios foram adaptadas segundo valores citados na literatura, sendo $10 \mathrm{mg}^{-1} \mathrm{~L}^{-1}$ para o cloreto férrico (BAGHVAND et al.,

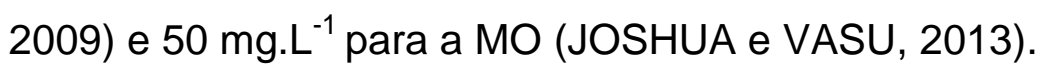

Baseado nas condições de operação ótimas da $\mathrm{MO}$, previamente estudadas por Cardoso et al. (2008); Madrona et al. (2010) e Valverde et al. (2013); e do cloreto férrico, obtidas através de informações na Sanepar, já que optou-se por adotar as condições reais de operação da ETA de Maringá, obteve-se as condições a serem avaliadas na associação dos coagulantes cloreto férrico e MO (Tabela 1).

Tabela 1. Condições de operação para a associação do cloreto férrico e MO

\begin{tabular}{|c|c|c|c|c|}
\hline Parâmetro & \multicolumn{4}{|c|}{ Valores } \\
\hline VMR & $100 \mathrm{rpm}$ & \multicolumn{2}{|c|}{$105 \mathrm{rpm}$} & $110 \mathrm{rpm}$ \\
\hline TMR & $1 \mathrm{~min}$ & \multicolumn{2}{|c|}{$2 \min$} & $3 \mathrm{~min}$ \\
\hline VML & $15 \mathrm{rpm}$ & \multicolumn{2}{|c|}{$30 \mathrm{rpm}$} & $45 \mathrm{rpm}$ \\
\hline TML & \multicolumn{4}{|c|}{$15 \min$} \\
\hline TS & $15 \min$ & $30 \mathrm{~min}$ & $45 \min$ & $60 \mathrm{~min}$ \\
\hline
\end{tabular}

A caracterização da água superficial foi realizada por meio dos seguintes parâmetros de qualidade: cor aparente, e compostos com absorção em $U_{254 n m}$ (espectrofotômetro DR $5000 \mathrm{Hach}$ ), turbidez (turbidímetro 2100P Hach), sólidos dissolvidos totais (APHA, 1995) e pH (pHmetro Thermo-Scientific VSTAR92 Orion Versastar).

A avaliação do processo de clarificação da água foi realizada baseada na redução 
percentual de cor aparente, turbidez e compostos com absorção em $U_{254 n m}$.

Para a avaliação da eficiência de remoção dos parâmetros de qualidade após o processo de clarificação da água, utilizou-se delineamento fatorial $27 \times 4$, sendo os fatores: ensaios (vinte e sete variações quanto às VMR, TMR, VML e TML) e tempos de sedimentação (quatro TS), com duas repetições.

Foram realizados para comparação dos resultados a Análise de Variância (ANOVA) e o teste de comparação de médias, teste Tukey, com 95\% de confiança, sendo significativo um $p$-valor $<0,05$, para verificar as diferenças significativas das eficácias de remoção, através do programa estatístico SISVAR versão 5.3.

\section{RESULTADOS E DISCUSSÕES}

A Tabela 2 apresenta os resultados da caracterização da água superficial utilizada nos ensaios de clarificação.

Tabela 2. Caracterização da água superficial

\begin{tabular}{|c|c|c|}
\hline Parâmetro de qualidade & Unidade & Água superficial \\
\hline Cor aparente & $\mathrm{uH}^{(1)}$ & 386 \\
\hline Turbidez & $\mathrm{NTU}^{(2)}$ & 72,9 \\
\hline Compostos com absorção em UV $254 \mathrm{~nm}$ & $\mathrm{~cm}^{-1}$ & 0,275 \\
\hline $\mathrm{SDT}^{(3)}$ & $m g \cdot L^{-1}$ & 71 \\
\hline $\mathrm{pH}$ & - & 7,813 \\
\hline
\end{tabular}

(1) Unidade Hazen: (mg Pt-Co L ${ }^{-1}$ )

(2) NTU: unidades nefelométricas de turbidez

(3) SDT: sólidos dissolvidos totais

Avaliando-se todos os resultados obtidos em relação às eficiências de remoção dos parâmetros cor, turbidez e compostos com absorção em $U_{254 n m}$, observa-se que não houve diferença estatisticamente significativa para as condições de operação apresentadas na Tabela 3. 
Tabela 3. Valores das eficiências de remoção para as melhores condições de operação na associação dos coagulantes

\begin{tabular}{|c|c|c|c|c|c|c|c|}
\hline \multicolumn{5}{|c|}{ Parâmetros } & \multicolumn{3}{c|}{ Eficiências de remoção (\%) } \\
\hline $\begin{array}{c}\text { VMR } \\
(\mathbf{r p m})\end{array}$ & $\begin{array}{c}\text { TMR } \\
(\mathbf{m i n})\end{array}$ & $\begin{array}{c}\text { VML } \\
(\mathbf{r p m})\end{array}$ & $\begin{array}{c}\text { TML } \\
(\mathbf{m i n})\end{array}$ & $\begin{array}{c}\text { TS } \\
(\mathbf{m i n})\end{array}$ & $\begin{array}{c}\text { Cor } \\
\text { aparente }\end{array}$ & Turbidez & UV $_{\mathbf{2 5 4 n m}}$ \\
\hline 100 & 3 & 30 & 15 & $15-60$ & $89,7-91,3$ & $90,8-92,4$ & $73,5-76,4$ \\
\hline 110 & 3 & 30 & 15 & 45 & 90,7 & 91,3 & 73,3 \\
\hline 105 & 2 & 45 & 15 & $15-45$ & $89,9-90,9$ & $91,7-92,1$ & $69,8-71,9$ \\
\hline 105 & 3 & 45 & 15 & $15 / 45-60$ & $92,7-93,9$ & $91,7-92,5$ & $72,5-75,0$ \\
\hline 110 & 3 & 45 & 15 & $30-60$ & $93,8-94,7$ & $92,7-93,2$ & $74,2-74,6$ \\
\hline
\end{tabular}

Segundo a literatura, estudos realizados somente com a MO relatam que a utilização desse extrato bruto não é adequada para grandes sistemas de abastecimento de água, já que o tempo de residência hidráulico é muito elevado (ALI et al., 2010). Madrona et al. (2010) e Valverde et al. (2013) obtêm resultados de remoção de cor aparente e turbidez com tempo de sedimentação (TS) de 60 min e 120 min, utilizando extrato de MO salina e aquosa, respectivamente.

Para resolver este problema, Bratby (2006) relata que, quando um polímero orgânico é adicionado como auxiliar de coagulação, o desempenho de floculação é significativamente melhorado no que diz respeito à remoção orgânica, densidade e sedimentação dos flocos. Segundo Ravikumar e Sheeja (2012), o TS para o pó de sementes de MO é mais longo do que quando se utiliza a associação dos coagulantes.

Em vista dos resultados obtidos, o TS de 15 min foi definido como o parâmetro, devido à sedimentação do tempo padrão usado em ETAs. Nesse caso, as seguintes condições de operação poderiam ser utilizadas: $100 \mathrm{rpm}$ durante 3 min e $30 \mathrm{rpm}$ durante $15 \mathrm{~min}$; ou $105 \mathrm{rpm}$ durante 2 ou $3 \mathrm{~min}$ e $45 \mathrm{rpm}$ durante $3 \mathrm{~min}$.

Em relação às velocidades de mistura, 100 rpm (VMR) e 30 rpm (VML) são mais vantajosas, por se tratarem das menores intensidades de agitação aplicadas ao processo de coagulação/floculação, o que está diretamente relacionado com a diminuição de gastos com energia. Segundo Julio et al. (2008), quanto maior o gradiente de velocidade, maiores serão os custos de implantação e operação em uma ETA. 
Assim, as condições de operação ótimas para a associação dos coagulantes $\mathrm{MO}$ e cloreto férrico são: 100 rpm (VMR), 3 min (TMR), 30 rpm (VML), 15 min (TML e TS).

\section{CONCLUSÕES}

O uso de coagulantes de origem vegetal, para a clarificação de água, quando possível, é de grande valia em termos ecológicos e ambientais. Assim, a MO se destaca como um promissor coagulante natural.

A associação dos coagulantes natural e químico contribui para a diminuição do tempo de sedimentação, sendo 15 min suficientes para a remoção dos parâmetros de qualidade avaliados.

Os parâmetros de mistura rápida e lenta, incluindo o tempo e intensidade da mistura, afetam a eficiência de remoção dos parâmetros de qualidade cor aparente, turbidez e compostos com absorção em $U^{254 n m}$, no processo de clarificação da água.

Assim, pode-se concluir que a associação dos coagulantes é uma alternativa vantajosa. Entretanto, ainda não é possível obter água potável somente com as etapas de coagulação/floculação e sedimentação, sendo necessário acrescentar as etapas de filtração e sedimentação para esse fim.

\section{AGRADECIMENTOS}

Os autores agradecem a CAPES pelo suporte financeiro; a Universidade Federal de Sergipe (UFS), pela doação das sementes de MO; e a SANEPAR, pelas amostras de água superficial fornecidas.

\section{REFERÊNCIAS}

ABALIWANO, J. K.; GHEBREMICHAEL, K. A.; AMY, G. L. Application of the purified Moringa oleifera coagulant for surface water treatment. WaterMill Working Paper Series, n. 5, p. 1-19, 2008.

ALI, E. N.; MUYIBI, S. A.; SALLEH, H. M.; ALAM, M. Z.; SALLEH, M. R. Production of natural coagulant from Moringa oleifera seed for application in treatment of low turbidity 
water. Journal Water Resource and Protection, v. 2, n. 3, p. 259-266, mar. 2010. doi:10.4236/jwarp.2010.23030.

AMAGLOH, F. K.; BENANG, A. Effectiveness of Moringa oleifera seed as coagulant for water purification. African Journal of Agricultural Research, v. 4, n. 1, p. 119-123, feb. 2009.

APHA. American Public Health Association. Standard methods for the examination for water and wastewater. $19^{\text {th }}$ ed. Washington, 1995.

BAGHVAND, A.; ZAND, A. D.; MEHRDADI, N.; KARBASSI, A. Optimizing coagulation process for low to high turbidity waters using aluminum and iron salts. American Journal of Environmental Sciences, v. 6, n. 5, p. 442-448, 2010.

BRATBY, Jonh. Coagulation and flocculation in water and wastewater treatment. $2^{\text {th }}$ ed. London, UK: IWA Publishing, 2006.

CARDOSO, K. C.; BERGAMASCO, R.; COSSICH, E. S.; MORAES, L. C. K. Otimização dos tempos de mistura e decantação no processo de coagulação/floculação da água bruta por meio da Moringa oleifera Lam. Acta Scientiarum Technology, Maringá, v. 3, n. 2, p. 193-198, 2008. doi:10.4025/actascitechnol.v30i2.5493.

DUBEY, D. K.; JYOTSNA, D.; KUMAR, A.; GULSAN, R. K. A multipurpose tree - Moringa oleifera. International Journal of Pharmaceutical and Chemical Sciences, v. 2, n. 1, p. 415-423, jan./mar. 2013.

GHEBREMICHAEL, K. A.; GUNARATNA, K. R.; HENRIKSSON, H.; BRUMER, H.; DALHAMMAR, G. A simple purification and activity assay of the coagulant protein from Moringa oleifera seed. Water Research, v. 39, n. 11, p. 2338-2344, jun. 2005.

JOSHUA, R.; VASU, V. Characteristics of stored rain water and its treatment technology using Moringa seeds. International Journal of Life Sciences Biotechnology and Pharma Research, India, v. 2, n. 1, p. 154-175, jan. 2013.

JULIO, M. de; FIORAVANTE, D. A.; OROSKI, F. I. Avaliação da influência dos parâmetros de mistura rápida, floculação e decantação no tratamento de água empregando o sulfato de alumínio e o PAC. Ciências Exatas e da Terra, Agrárias e Engenharias, v. 14, n. 2, p. 109-120, ago. 2008. doi:10.5212/Publ.Exatas.v.14i2. 109120.

LEA, M. Bioremediation of turbid surface water using seed extract from Moringa oleifera Lam. (drumstick) tree. Current Protocols in Microbiology, Wiley Interscience, p. 1-14, feb. 2010. doi:10.1002/9780471729259.mc01g02s16.

LO MONACO, P. A. V.; MATOS, A. T.; RIBEIRO, I. C. A.; NASCIMENTO, F. S.; SARMENTO, A. P. Utilização de extrato de sementes de Moringa como agente 
coagulante no tratamento de água para abastecimento e águas residuárias. Ambi-Agua, Taubaté, v. 5, n. 3, p. 222-231, 2010. doi:10.4136/ambi-agua.164.

MADRONA, G. S.; SERPELLONI, G. B.; SALCEDO, A. M.; NISHI, L.; CARDOSO, K. C.; BERGAMASCO, R. Study of the effect of saline solution on the extraction of the Moringa oleifera seeds active component for water treatment. Water, Air \& Soil Pollution, v. 211, n. 1-4, p. 409-415, sep. 2010. doi:10.1007/s11270-009-0309-0.

MANGALE SAPANA, M.; CHONDE, S. G.; RAUT, P. D. Use of Moringa oleifera (drumstick) seed as natural absorbent and an antimicrobial agent for ground water treatment. Research Journal of Recent Sciences, v. 1, n. 3, p. 31-40, mar. 2012.

NDABIGENGESERE, A.; NARASIAH, K. S. Quality of water treated by coagulation using Moringa oleifera seeds. Water Research, v. 32, n. 3, p. 781-791, mar. 1998. doi:10.1016/ S0043-1354(97)00295-9.

PISE, C. P.; HALKUDE, D. S. A. Blend of natural and chemical coagulant for removal of turbidity in water. International Journal of Civil Engineering and Technology, v. 3, n. 2, p. 188-197, jul./dec. 2012.

PRITCHARD, M.; CRAVEN, T.; MKANDAWIRE, T.; EDMONDSON, A. S.; O'NEILL, J. G. A comparison between Moringa oleifera and chemical coagulants in the purification of drinking water - An alternative sustainable solution for developing countries. Physics and Chemistry of the Earth, v. 35, n. 13-14, p. 798-805, jul. 2010. doi:10.1016/j.pce.2010.07. 014.

RAVIKUMAR, K.; SHEEJA, A. K. (2012). Water clarification using Moringa oleifera seed coagulant. In: International Conference on Green Technology, pp. 64-70, dec. 2012, Trivandrum, India. doi: 10.1109/ICGT.2012.6477949

VALVERDE, K. C.; MORAES, L. C. K.; BONGIOVANI, M. C.; CAMACHO, F. P. BERGAMASCO, R. Coagulation diagram using the Moringa oleifera Lam and the aluminium sulphate, aiming the removal of color and turbidity of water. Acta Scientiarum Technology, Maringá, v. 5, n. 3, p. 485-489, jul./sep. 2013. doi:10.4025/actascitechnol. v35i3.12268. 